\title{
Dermoid cyst of great wing of sphenoid bone
}

\author{
ALY MORTADA \\ Department of Ophthalmology, Faculty of Medicine, Cairo University, Egypt
}

Hartmann and Gilles (1959), Reese (1963), and Duke-Elder (1964) have described the $x$-ray picture of deep orbital dermoid cysts, stressing the importance of their exact localization for proper surgical treatment. Among nine cases reported by Pfeiffer and Nicholl (1948) there were seven affecting the frontal bone, and two the lateral wall of the orbit or great wing of the sphenoid bone.

The following case is described because such cysts very rarely affect the diploic bone of the great wing of the sphenoid bone.

\section{Case report}

A 16-year-old girl (Fig. I) had right downwards and inwards proptosis of $20 \mathrm{~mm}$. (left side $16 \mathrm{~mm}$. Hyrtel) of ro months' duration. There was no ocular pain and no limitation of ocular movements. The right and left fundi were normal, and the visual acuity 6/12. There was no external palpable orbital mass. The general condition of the patient was good.

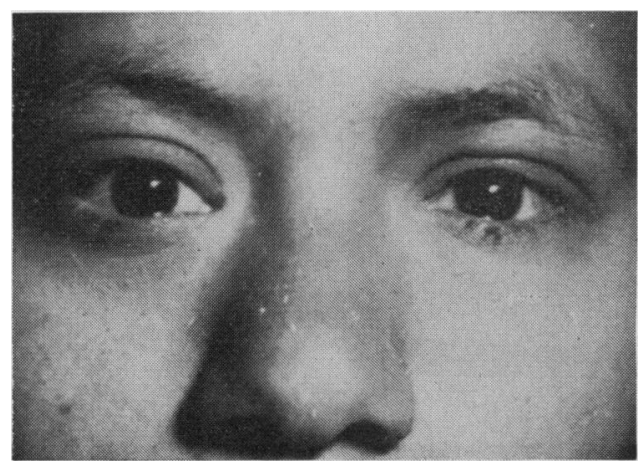

FIG. I Case I. Right proptosis due to dermoid cyst in diploic bones of right great wing of sphenoid bone of 10 months' duration in a girl aged 16 years

\section{Examination}

Postero-anterior (Fig. 2), lateral, and oblique (Fig. 3) skull $x$ rays (overleaf) showed widening of the right orbit and an area of loss of substance with a dense smooth sharply-defined margin affecting the right great wing of the sphenoid bone, thus suggesting a dermoid cyst. Both optic foramina were of normal dimensions.

Deep orbital palpation with the little finger through an external canthotomy incision showed that the bony reaction was due to extensions of the dermoid cyst into the diploic bones with irregularity and thickening of the great wing of the sphenoid bone.

\section{Treatment}

As removal of the great wing of the sphenoid bone with the contained dermoid cyst would endanger the brain in the middle cranial fossa the following treatment was adopted in accordance with the advice of Pfeiffer and Nicholl (1948). Through a lateral orbitotomy the cyst was incised and e racuated. Its inner wall was swabbed with carbolic acid and immediately neutralized by alcohol and irrigated by saline solution. The cyst wall was then removed as completely as possible. 

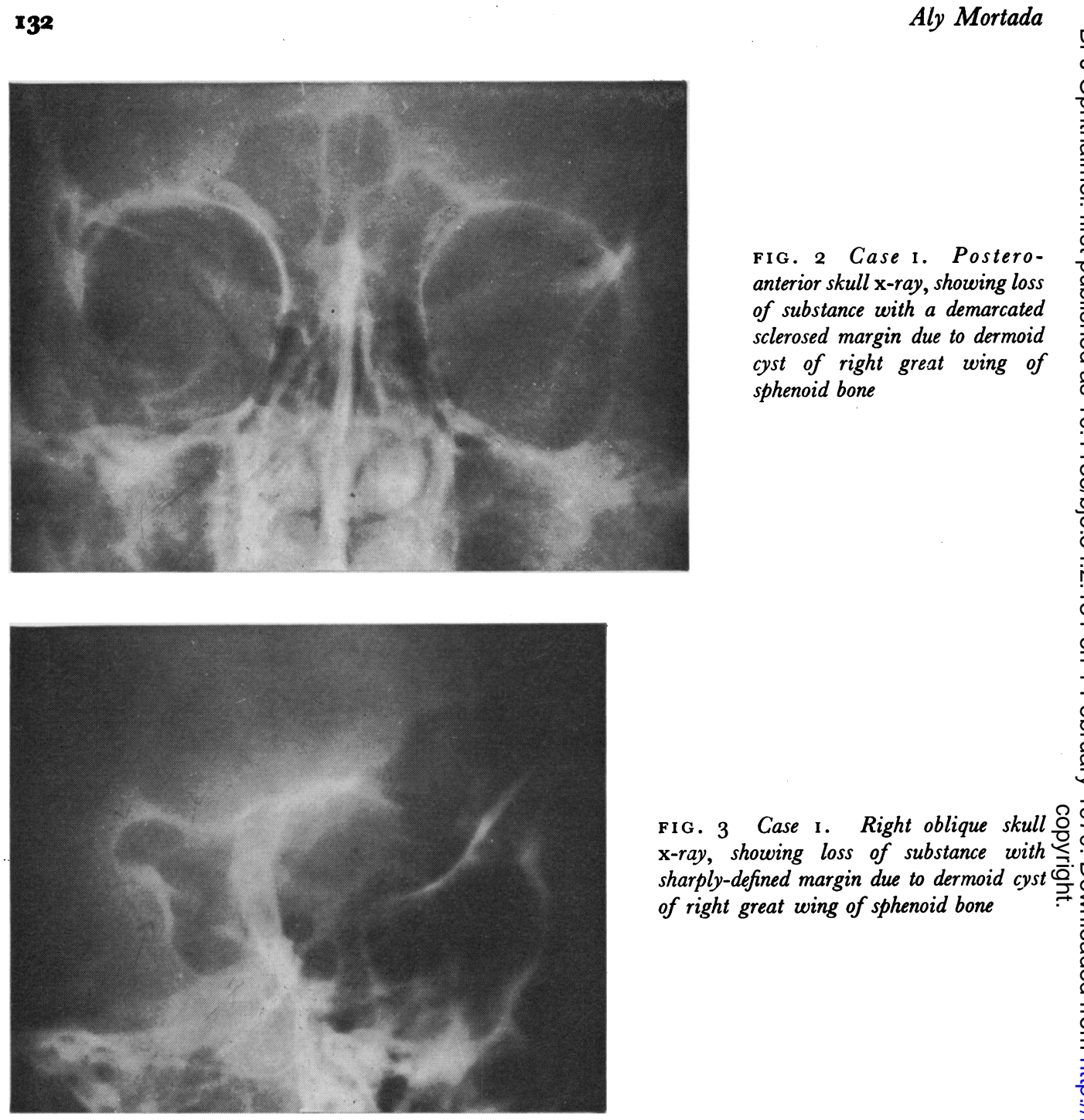

FIG. 3 Case I. Right oblique skull 0 $\mathrm{x}$-ray, showing loss of substance with sharply-defined margin due to dermoid cyst of right great wing of sphenoid bone

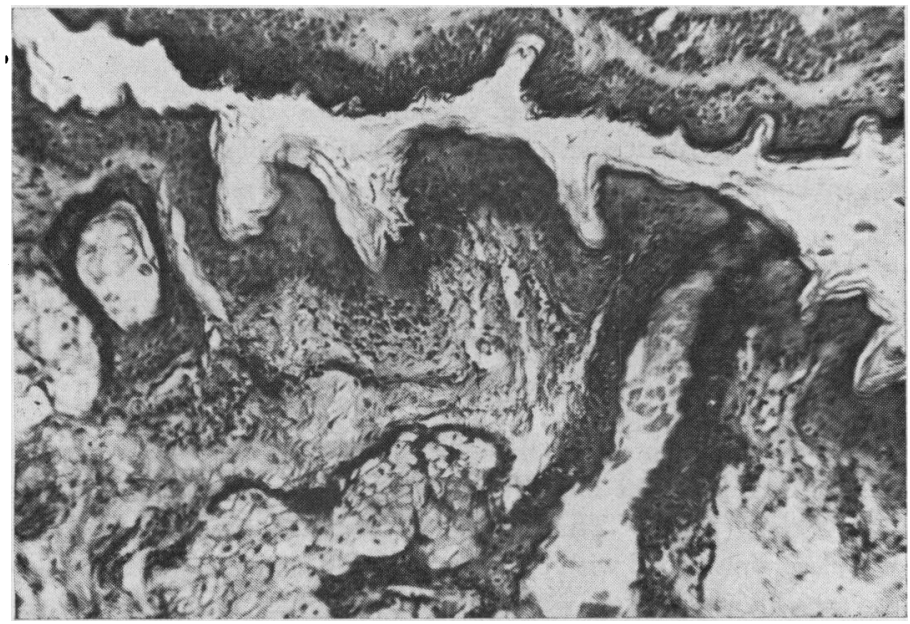

Fig. 4 Case I. Dermoid cyst of right great wing of sphenoid bone, showing epidermis and dermis containing sweat and sebaceous glands and hair follicles. $\times 120$ 


\section{Histopathology}

The cyst wall showed epidermis and dermis containing sweat and sebaceous glands and hair follicles (Fig. 4). The cyst contained a brownish semi-fluid and hairs.

\section{Summary}

A deep orbital dermoid cyst affecting the diploë of the right great wing of the sphenoid bone caused proptosis in a 16 -year-old girl.

\section{References}

DUKE-ELDER, s. (1964) "A System of Ophthalmology", vol. 3, part 2, p. 957. Kimpton, London hartmanN, E., and Gilles, E. (1959) "Roentgenologic Diagnosis in Ophthalmology", trans. G. Z. Carter, ed. C. Berens, p. 7r. Lippincott, Philadelphia

PFeIfFer, R. L., and Nicholl, R. J. (1948) Trans. Amer. ophthal. Soc., 46, 218

REESE, A. B. (1963) "Tumors of the Eye", 2nd ed., p. 509. Harper and Row, New York, Evanston, and London 